\title{
The effects of low frequency, whole body vibration on rats: Prolonged training, predictability, incremental training, and taste conditioning
}

\author{
EDWARD L. WIKE, VIRGINIA L. WOLFE, and KIRK A. NORSWORTHY \\ The University of Kansas, Lawrence, Kansas 66045
}

\begin{abstract}
Five experiments were done on the effects of low frequency whole body vibration on rats. In Experiment I, it was found that vibration mediated escape learning throughout a 50-day period. Predictable vibration (Experiment II) and incremental training (Experiment III) were observed to produce less escape responding than random unpredictable vibration. In Experiments IV and V, taste conditioning was studied using vibration as an US. It was concluded that vibration is an aversive stimulus like shock which mediates escape conditioning but not taste conditioning.
\end{abstract}

In a series of prior studies (Wike \& Wike, 1972), it was shown that rats learned and maintained a lever response which produced temporary cessations of low frequency, whole body vibration delivered by the vertically oscillating floor of a modified Skinner box. Experiments by Hunt and Quay (1961) and Soskin (1963) have also suggested that vibration is aversive. Hunt and Quay reported that naive rats would barpress to turn off vibration and Soskin found that subjects, both with and without previous exposure to vibration, preferred a nonvibrating goalbox over a vibrating goalbox in U-maze tests.

The aim of the present studies was to investigate the effects of several additional vibration parameters upon escape conditioning and to determine whether or not low frequency, whole body vibration could serve as a US for taste conditioning.

\section{EXPERIMENT I}

The purpose of this experiment was to investigate the effect of prolonged exposure to vibration. In earlier studies rats were vibrated for $20 \mathrm{~min}$ daily for a maximum of 12 days in an escape conditioning paradigm in which each barpress shut off vibration for $10 \mathrm{sec}$. In the present study, subjects were exposed to vibration for 50 days.

\section{Method}

Subjects. The subjects were eight naive male Holtzman albino rats whose body weights ranged from 258 to $293 \mathrm{~g}$ at the start of the study. They were housed in individual cages and maintained ad lib on Purina Lab Chow and water.

Apparatus. The modified Skinner box is described more fully elsewhere (Wike \& Wike, 1972). In brief, the floor was

This research was supported by BMD Grant 4921-5706-7 and a grant from the General Research Fund of the University of Kansas. Requests for reprints should be addressed to the senior author at the Department of Psychology, University of Kansas, Lawrence, Kansas 66045 . suspended by elastic straps and vibrated by a permanent magnet vibrator which was driven by a solid-state power amplifier. The $8-\mathrm{Hz}, .61-\mathrm{cm}$ peak-to-peak vibrations were terminated for $10 \mathrm{sec}$ after each barpress and responses during the time-out periods had no consequence. Barpresses were accumulated on digital counters.

Procedure. The subjects were randomly and equally assigned to two treatments. The vibration subjects received 20 -min tests daily for 50 days. Control subjects were placed in the box for 20 min without vibration for the first 30 days. In the last 20 days they were exposed to 20 -min intermittent vibration in which $5 \mathrm{~min}$ of vibration was alternated with $30 \mathrm{sec}$ of nonvibration.

\section{Results}

The vibration subjects improved in barpressing over the first 30 days of testing; the $\mathrm{M}$ barpresses was 38.8 on Day 1 and 89.8 on Day 30. Meanwhile, the nonvibrated subjects never made more than a $\mathrm{M}$ of 3.5 barpresses per day. In the last 20 days the performance of the vibration subjects remained stable $(M=87.7)$ and the control subjects with intermittent vibration improved rapidly (M $=54.1$ ), but never attained the levels of the vibration subjects in either the first or last 20 days. The lower performance, however, was due largely to one control subject which never learned to barpress. It may be concluded that with long-term exposure vibration does not become less aversive.

\section{EXPERIMENT II}

Glass and Singer (1972) have presented evidence that for a variety of aversive stimuli unpredictable stimuli are more stressful than predictable ones. The aim of this study was to assess this hypothesis by presenting vibration on a VI vs. FI schedule. If the hypothesis is true, then we would anticipate greater barpressing on the VI schedule.

\section{Method}

Subjects. Eight rats of the same strain, sex, and weight as in 
Experiment I were randomly and equally assigned to the two treatments.

Apparatus. The vibration was programmed in the same apparatus by either a VI or FI tape. In VI the vibration was on for a $M=2 \mathrm{~min}$ and off for a $M=2 \mathrm{~min}$ so that the subjects received a total of $10 \mathrm{~min}$ of vibration in the 20 -min tests. In the FI condition, 2-min on periods and 2-min off periods were alternated.

Procedure. The subjects had 20-min tests daily for 40 days under either VI or FI vibration. Each barpress led to a 10-sec respite from vibration.

\section{Results}

Although both groups began at the same low levels of barpressing, the VI group $(M=41.9)$ soon exceeded the FI group $(M=32.1)$ and retained its superiority throughout the course of training $(\mathrm{F}=7.77 \mathrm{df}=1 / 6$, $\mathrm{p}<.05)$. Vibration, like other aversive stimuli, appears to be more stressful when presented in an unpredictable fashion.

\section{EXPERIMENT III}

There is evidence (e.g., Miller, 1960; Davis \& Wagner, 1969) that gradual exposure to an aversive stimulus (incremental training) is less stress inducing than random presentation. If this hypothesis is valid for vibration, then fewer barpresses would be expected with incremental training.

\section{Method}

Subjects. The 16 subjects of the same strain, sex, and weight as in Experiment I were randomly and equally assigned to the two treatments.

Apparatus. The same apparatus was used as in Experiment $\mathrm{I}$.

Procedure. The study consisted of a 5-day training phase followed by a 10-day test phase. The incremental training subjects had gradually increasing amplitudes of vibration produced by adjusting the amplifier power setting to $.2 \mathrm{~A}$ (Day 1), .6A (Day 2), 1.3A (Day 3), 1.6A (Day 4), and 2.0A (Day 5). The subjects in the random group received the same power settings with a different randomized order for every subject. At all power settings, the vibration frequency was $8 \mathrm{~Hz}$ and the amplitude was increased to a maximum of $.61-\mathrm{cm}$ peak-to-peak at 2.0A. During the test phase both groups received a 2.0-A setting, and in both phases 20 -min daily tests were imposed in which each barpress terminated vibration for $10 \mathrm{sec}$.

\section{Results}

For all subjects the median numbers of barpresses were obtained for each 5-day block of tests. Overall the random subjects made more barpresses $(M=48)$ than the incremental subjects $(M=28.9)$ but the difference bordered on significance $(\mathrm{F}=4.42, \mathrm{df}=1 / 14$, $.10>p>.05)$. Since the variances within each group were greatly inflated by two subjects (one in each group), which performed below the baseline levels for no vibration, the data were re-analyzed with these subjects omitted. In training, the random subjects $(M=28.4)$ barpressed significantly more $(\mathrm{F}=5.07, \mathrm{df}=1 / 12$, $\mathrm{p}<.05)$ than the incremental subjects $(\mathrm{M}=9.4)$. Similarly, in the first 5 days of test the random subjects
$(\mathrm{M}=66.6)$ were superior $(\mathrm{F}=4.77, \mathrm{df}=1 / 12, \mathrm{p}<.05)$ to the incremental subjects $(M=39.2)$. In the last 5 days of test, the difference between the two groups $(\mathrm{M}=73.5$ vs. $\mathrm{M}=50.9)$ again approached significance $(\mathrm{F}=4.53 \mathrm{df}$ $=1 / 12, .10>\mathrm{p}>.05)$. These data, using vibration, are consonant with the generalization based upon other aversive stimuli that an aversive stimulus is less stressful when it is presented in an incremental fashion rather than randomly.

\section{EXPERIMENTS IV AND V}

The robust conditioning of taste CSs with nausea-inducing substances as USs in rats has been amply documented (Seligman \& Hager, 1972). Braun and McIntosh (1973) have produced taste aversions by pairing salt and sucrose solutions with rotational stimulation that they inferred induced nausea. It has been suggested to us that vibration is aversive because it produces nausea. If this assumption is true, then aversion conditioning should occur when vibration is paired with distinctive tastes. The aim of the present experiment was to evaluate this assumption.

\section{Method}

Subjects. There were 12 subjects in each study, and they were of the same strain, sex, and size as in Experiment $I$. The subjects were randomly and equally assigned to two treatments: sucrose-vibration and salt-no vibration vs. sucrose-no vibration and salt-vibration. In both experiments subjects had ad-lib access to Purina Lab Chow in their individual living cages. In Experiment IV, subjects had ad-lib access to water in their cages when they were not being tested; in Experiment IV, subjects did not.

Apparatus. The apparatus consisted of a set of eight cages (each cage, $33 \times 23 \times 25 \mathrm{~cm}$ ) which were vibrated by an air-driven mechanism (cf. Swift, 1973, for a full description). Adjoining the vibrating cages was an identical set of nonvibrating cages. The vibration frequency was $4 \mathrm{~Hz}$ and the amplitude was $.61 \mathrm{~cm}$ peak-to-peak in Experiment IV and $1.9 \mathrm{~cm}$ peak-to-peak in Experiment V.

Procedure. Each night subjects were presented with either a sucrose solution $(50 \mathrm{~g} / \mathrm{liter})$ or a salt solution $(9 \mathrm{~g} / \mathrm{liter})$-the same mixtures used by Braun and McIntosh-in 100-ml drinking tubes in the subjects' individual living cages for $20 \mathrm{~min}$. After a 6-day baseline to accustom the subjects to the solutions, in which the solutions were alternated nightly, taste conditioning began by putting the sucrose-vibration subjects, which had just drunk sucrose, into the vibrating cages for $20 \mathrm{~min}$ and the salt-vibration subjects into the nonvibrating cages. On the next night following salt solution intake, the salt-vibration subjects were vibrated for $20 \mathrm{~min}$ and the sucrose-vibration subjects were placed in the nonvibrating cages. Three such cycles of training ( 6 days) were given in Experiment IV and eight cycles in Experiment V. Throughout baseline and training subjects' intakes of the solutions were measured nightly. After training the subjects received 20-min preference tests in the home cages in which both solutions were presented side-by-side. Half of the subjects in each group had sucrose on the right and salt on the left; the remaining subjects received the solutions on the opposite side.

\section{Results}

In contrast to the results of Braun and McIntosh, who 
observed a significant decrement in the intake of the solution paired with rotation, in neither experiment did vibration have any consistent effect on solution intake. Mcreover, in the preference tests, the subjects displayed a consistent choice of sucrose over salt (11 out of 12 subjects in Experiment IV and 9 out of 12 subjects in Experiment V). The solutions, which were equally preferred by Braun and McIntosh's rats, were not by our subjects. In brief, no evidence was found in either experiment for vibration's being an effective US for taste conditioning.

\section{DISCUSSION}

The first three experiments provide additional evidence that low frequency, whole body vibration is aversive to rats. It is clear from Experiments I and II that vibration retains its aversive character over long periods of time (50 and 40 days, respectively). In accord with findings on other aversive stimuli, predictable vibration was found to be less aversive than unpredictable vibration (Experiment II), and incremental training involving increasing vibration amplitudes was less stressful than random presentations of the same amplitudes (Experiment III). In part, the ameliorating effect of incremental training may be a consequence of its predictability. However, since decremental training, which is equally predictable, has been shown to be less beneficial in other studies, the efficacy of incremental training cannot be accounted for solely in terms of its predictability.

In Experiment IV, no evidence was observed for vibration's serving as an effective US for taste conditioning. In Experiment V, the duration of training and amplitude of vibration were increased but again the results were negative.
While it is possible that longer durations of vibration might lead to taste conditioning, we suspect that rotational stimulation rather than $\mathrm{Z}$-axis vibration is necessary for movement-induced nausea. Accordingly, vibration appears to be an aversive stimulus like mild shock which mediates escape conditioning but does not mediate taste conditioning.

\section{REFERENCES}

Braun, J. J., \& McIntosh, H., Jr. Learned taste aversions induced by rotational stimulation. Physiological Psychology, 1973, 1, 301-304.

Davis, M., \& Wagner, A. R. Habituation to startle response under incremental sequence of stimulus intensities. Journal of Comparative and Physiological Psychology, 1969, 67, 486-492.

Glass, D. C., \& Singer, J. E. Urban stress: Experiments on noise and social stressors. New York: Academic Press, 1972.

Hunt, J. M., \& Quay, H. C. Early vibratory experience and the question of innate reinforcement value of vibration and other stimuli: A limitation on the discrepancy (burnt soup) principle in motivation. Psychological Review, 1961, 68, 149-156.

Miller, N. E. Learning resistance to pain and fear: Effects of overlearning, exposure, and rewarded exposure in contest. Journal of Comparative and Physiological Psychology, 1960, 60, 137-145.

Seligman, M. E. P., \& Hager, J. L. (Eds.) Biological boundaries of learning. New York: Appleton-Century-Crofts, 1972.

Soskin, R. A. The effects of early experiences upon the formation of environmental preferences in rats. Journal of Comparative and Physiological Psychology, 1963, 56, 303-306.

Swift, C. F. The effect of low-frequency whole-body vibration on the alcohol consumption of rats. Unpublished $\mathrm{PhD}$ dissertation. University of Kansas, 1973.

Wike, E. L., \& Wike, S. S. Escape conditioning and low-frequency whole-body vibration: The effects of frequency, amplitude, and controls for noise and activation. Psychonomic Science, 1972, 27, 161-163.

(Received for publication January 6, 1975.) 